\title{
The influence of vertical shear on the hogging bending moment resistance of ComFlor composite slabs
}

\author{
R. Abspoel ${ }^{a *}$, J.W.B. Stark ${ }^{a}$ and H.-J. Prins ${ }^{b}$

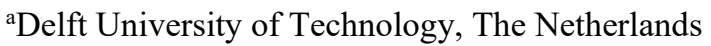 \\ ${ }^{b}$ Dutch Engineering BV, The Netherlands \\ *corresponding author, e-mail address: r.abspoel@tudelft.nl
}

\begin{abstract}
Composite slabs are designed to transfer loads in one direction e.g. the longitudinal direction of the ribs. To reduce the deflection, it is useful to realise a continuous slab with at least one intermediate support. At the intermediate support in addition to a hogging bending moment a rather large vertical shear force will act. For the verification of the combination of vertical shear and bending clause 9.7.5 of EN1994-1-1 [1] refers to clause 6.4.4 of EN1992-1-1 [2]. However in EN1992-1-1 there is no requirement related to interaction between vertical shear and a sagging or hogging bending moment. Implicitly this implies that interaction may be neglected and that bending moment and shear force may be verified separately.

In practice checking authorities not always accept this interpretation of the code and require proof that interaction may be neglected. So Tata Steel Panels and Profiles with Dutch Engineering r.i. BV commissioned Stevin II laboratory of Delft University of Technology to carry out a research program to investigate this interaction. A test program was carried out to gain more insight in the interaction and to find out whether design calculations should take into account $\mathrm{M}-\mathrm{V}$ interaction when applying the ComFlor series. Two series of respectively three and two test specimens were conducted, namely on ComFlor 210 (TS1 up to TS3) and ComFlor 75 (Tata Steel Panels and Profiles reference ComFlor 60) (TS4 and TS5) produced by Tata Steel Panels and Profiles and supplied by Dutch Engineering r.i. BV in the Benelux.

A second point of interest is the contribution of the steel deck to the vertical shear resistance. The reference in clause 9.7.5 of EN1994-1-1 to EN1992-1-1 without mentioning EN1993 causes that in practice only the contribution of the concrete rib is taken into account, the steel deck is neglected completely. This is, of course, a simplification of the actual behaviour.
\end{abstract}

Keywords: Composite slab; vertical shear; hogging bending moment resistance.

\section{Introduction}

Composite slabs are built up with a thinwalled cold-formed steel deck and interconnected with a concrete topping. Steel decks can be subdivided into two groups, namely shallow decks and deep decks. In EN1994 [1] a subdivision is given based on the spacing of the webs. EN1994 covers only narrow spaced webs which are defined by the ratio $b_{r} / b_{s}$, where $b_{r}$ is the width of the upper flange and $b_{s}$ is the distance between centres of adjacent ribs. The recommended value for the upper limit of this ratio is $b_{r} / b_{s}=0.6$.

For the deep deck ComFlor 210 see Fig. 1 and for the shallow deck ComFlor 75 see Fig. 2.

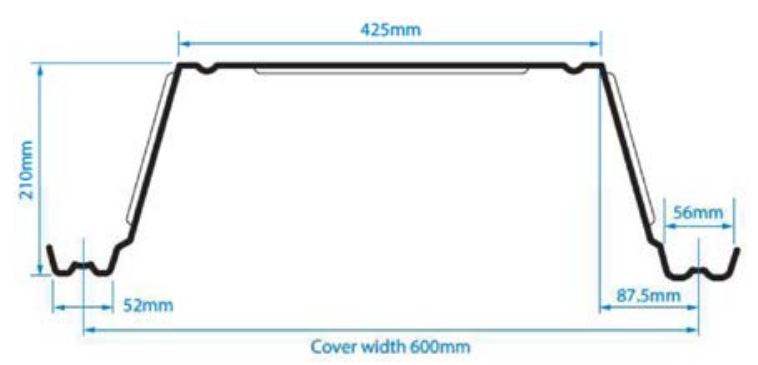

Fig. 1. Deep deck ComFlor 210. 
ComFlor 210 has a ratio $b_{r} / b_{s}=425 / 600=0.71$ and is consequently not covered in EN1994.

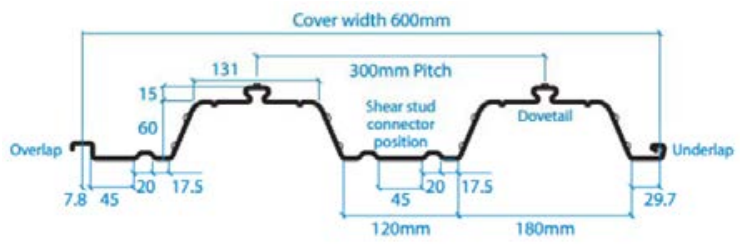

Fig. 2. Shallow deck ComFlor 75.

ComFlor 75 has a ratio $b_{r} / b_{s}=131 / 300=0.44$ and so fulfils the requirement related to this spacing.

As mentioned in the Absract, at the intermediate support in addition to a hogging bending moment a rather large vertical shear force will act, see Figure 3.

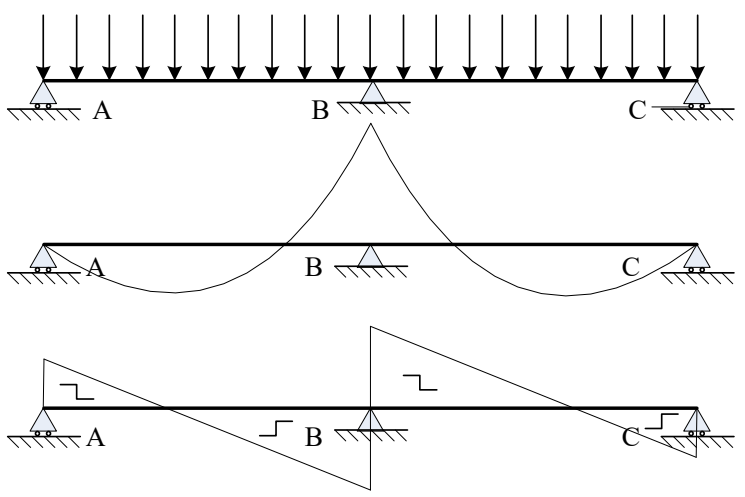

Fig. 3. Bending moment and shear distribution.

In this paper the results are given of a test program, carried out to gain more insight in the interaction between moment and shear when applying the ComFlor series. Two series tests were conducted, namely 3 tests on ComFlor 210 and 2 tests on ComFlor 75.

These tests also provided information about the contribution of the steel deck to the vertical shear resistance.

In Stark, J.W.B. and Stark, R. [3] is concluded that if rib reinforcement is used, the vertical shear resistance of ComFlor 75 may be determined as the sum of the vertical shear resistance of the decking profile and the vertical shear resistance of the concrete components. Hartmeyer [4] also proved that for the investigated decking profiles the vertical shear resistance is the sum of the vertical shear resistance of the decking profile and the vertical shear resistance of the concrete components. This means that the vertical shear resistance according to EN1994-1-1 obvious is an underestimation of the real resistance.

\section{Test program}

\subsection{Test set-up}

The test set-up is designed in such a way that a combination of hogging bending moment and vertical shear can be applied on a relative short test specimen. The mechanical scheme is in principle a simply supported beam with a large cantilever on one side, see Fig. 4.

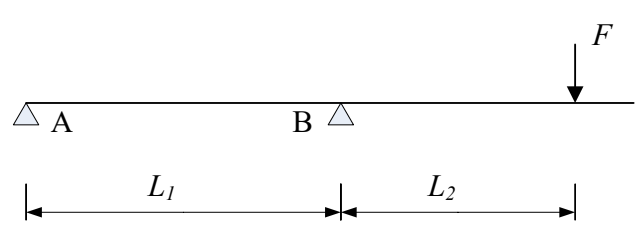

Fig. 4. Static scheme laboratory tests.

The load is applied on the overhang by a hydraulic jack, positioned at a variable distance $\mathrm{L}_{2}$ to support B, see Fig. 4. A line load is created by connecting the hydraulic jack to a spreader beam. By varying the position of the hydraulic jack different combinations of hogging bending moment and vertical shear can be realised. A minimum distance for L2 is assumed to be 3 times the total height of the composite slab. This to avoid that part of the load is transferred directly to the support.

In addition to the effect of the line load also the dead weight of the overhang is taken into account for the calculation of $M$ and $V$, see chapter 3. Fig. 5 shows an overview of the test rig with a test specimen.

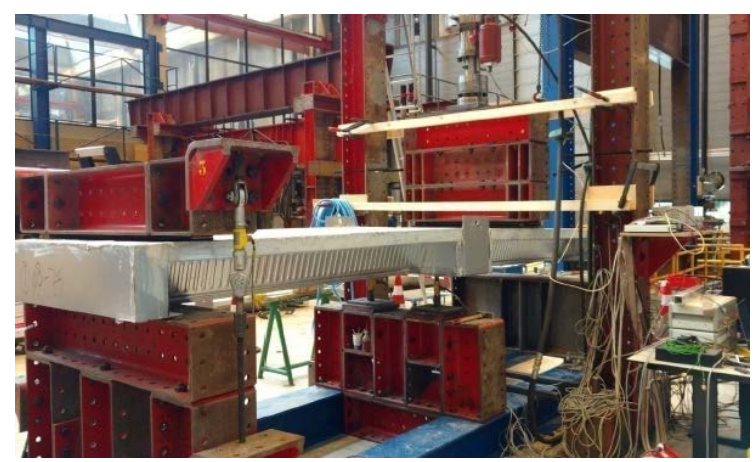

Fig. 5. A test specimen in the test rig.

\subsection{Test specimens}

During casting and hardening of the concrete the steel decks were supported at the ends and at midspan.

The test specimens of the first series consist of two steel decks ComFlor 210 with a nominal 
concrete topping of $70 \mathrm{~mm}$ and a reinforcement mesh of \#8-150 with additional rebars Ø8-150 in TS 1 and 2 and with additional rebars $\varnothing 10$ 150 in TS 3. One rebar Ø12 is placed in both ribs. The length of all three test specimens is $4210 \mathrm{~mm}$ and the number of ribs is 2 , so the slabs have a width of $1.2 \mathrm{~m}$, see Fig. 6 .

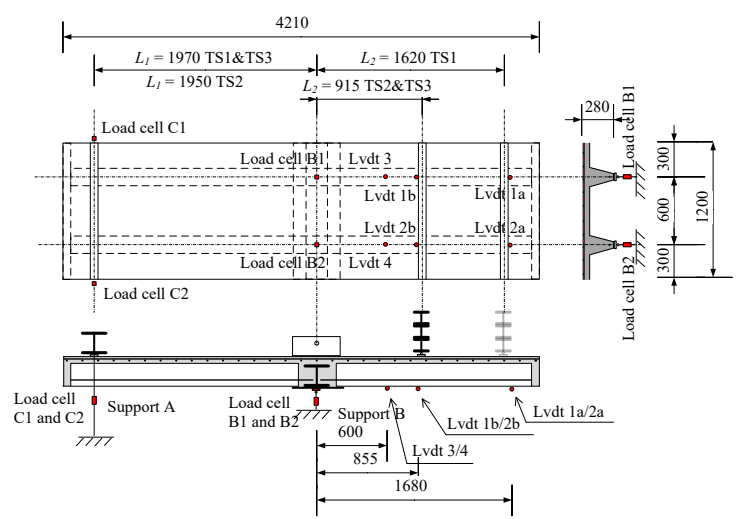

Fig. 6. Overview of a test specimen of series 1

At the bottom flange of the rib the decks overlap and are nailed together. To create a test specimen two deck plates were used. One of the decks could be used immediately, without any tooling, while the second deck is cut in half at the centre across the longitudinal axis and then each half forms a side of the test specimen.

The span L1 between supports A and B is $1970 \mathrm{~mm}$ for TS 1 and 3 and $1950 \mathrm{~mm}$ for TS 2. The distance L2 is $1620 \mathrm{~mm}$ for TS1 and 915 $\mathrm{mm}$ for TS2 and TS3.

The ComFlor 210 test specimens have a support B built up with a HE200A section with an additional plate of $400 \times 1200 \times 10 \mathrm{~mm}^{3}$ welded on the bottom flange, see Figure 7 . This section is encased in concrete with a width of $400 \mathrm{~mm}$.

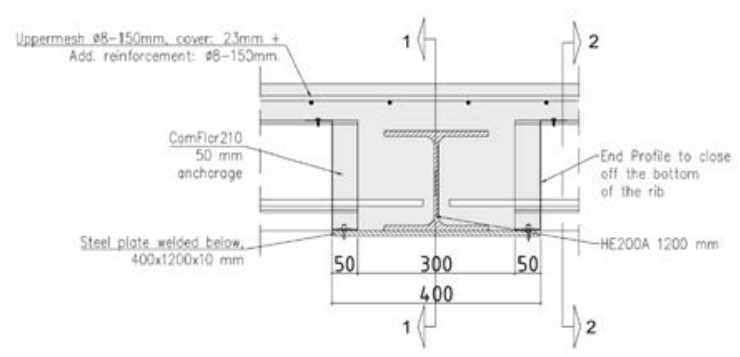

Fig. 7. Cross-section at support B (ComFlor 210).

Support A consists of two parts, namely one to support the dead load of the slab during preparation of the laboratory tests and one part to support the slab during testing with a concentrated load at the overhang. The direction of the reaction force related to the dead load is downwards, while the direction of the reaction force related to the concentrated load is upwards. The upward reaction force is resisted by a beam at the top of the slab, connected by anchor threads to the floor of the laboratory, see Fig. 5 and 6.

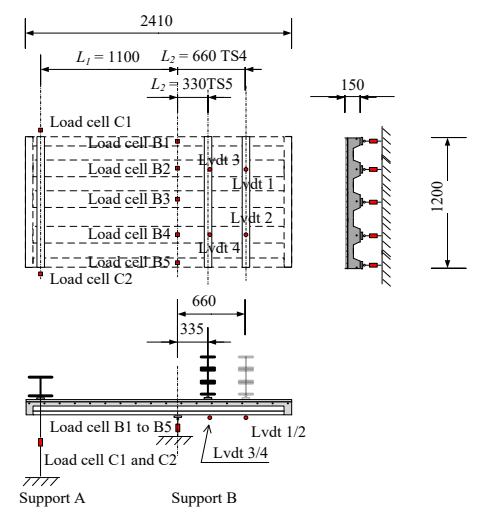

Fig. 8. Overview of a test specimen of series 2 .

The two test specimens of the second series consist of a steel deck ComFlor 75 with a nominal concrete topping of $90 \mathrm{~mm}$ and a reinforcement mesh of \#8-150 with additional bars $\varnothing 8-150$ in the topping. The slab is continuous over support B, see Fig. 8. The length of both test specimens is $2410 \mathrm{~mm}$ and the number of ribs is 4 , namely 3 whole ribs and 2 half ribs so the width of the specimens is $1200 \mathrm{~mm}$ too.

The span L1 between supports A and B is $1100 \mathrm{~mm}$. The distance L2 is $660 \mathrm{~mm}$ for TS1 and $330 \mathrm{~mm}$ for TS2 and TS3. A plan and cross-sections are shown in Fig. 8.

\subsection{Instrumentation}

The instrumentation for TS1, TS2 and TS3 is shown in Fig. 6 and for TS4 and TS5 in Fig. 8 . The reaction forces of the ribs at support $B$ of both test series are measured individually and the reaction forces of support A are measured by two load cells connected to both thread anchors connecting the supporting beam at the top of the specimen. These reaction forces are not necessary for the determination of the interaction between hogging bending moment $M$ and vertical shear $V$, because this depends on the load of the actuator and the dead load at the overhang only. The measurements of the reaction forces and the Ldvt's are of interest to check the test rig. 


\subsection{Material properties}

The steel and concrete classes specified for the test specimen are:

- Steel deck strength grade S350

- Concrete strength class C30/37

- Reinforcement steel grade B500

The real material properties are obtained by standard material tests.

Table 1 shows the relevant material properties .

Table 1.The material properties of the reinforcement bars

\begin{tabular}{cccc}
\hline Variable & Test 1 & Test 2 & Test 3 \\
\hline$\sigma_{0.2}[\mathrm{MPa}]$ & 541 & 536 & 543 \\
$f_{u}[\mathrm{MPa}]$ & 583 & 574 & 577 \\
$f_{u} / \sigma_{0.2}[-]$ & 1.08 & 1.07 & 1.06 \\
\hline
\end{tabular}

For the yield strength of the steel deck the following values given in the certificates of Tata Steel are used;

- ComFlor $210: \mathrm{f}_{\mathrm{y}}=409 \mathrm{~N} / \mathrm{mm}^{2}$

- ComFlor $75: \mathrm{f}_{\mathrm{y}}=402 \mathrm{~N} / \mathrm{mm}^{2}$

Concrete cubes of size $150 \mathrm{~mm}$ were casted at the same moment that the test specimens were casted and cured under the same conditions. The material properties were obtained at the day each test was performed, see Table 2.

Table 2.Compressive strength of concrete

\begin{tabular}{cccccc}
\hline \multicolumn{1}{c}{ Var. } & TS1 & TS 2 & TS3 & TS4 & TS5 \\
\hline Day [-] & 4 Oct & 6 Oct & 12 Oct & 19 Oct & 20 Oct \\
$\sigma_{a v}[\mathrm{MPa}]$ & 39.9 & 41.5 & 41.8 & 42.1 & 43.6
\end{tabular}

\subsection{Actual resistances}

The actual resistances depends on the actual material properties, see Tables 1 and 2, and the actual dimensions as identified in Fig. 9 for series 1 and Fig. 10 for series 2. The values of these dimensions are summarised in Table 3.

Fig. 6 and 7 show that the steel deck ComFlor 210 is not contributing to the hogging bending moment resistance, because the deck is not continuous over support B. The bending moment resistance is based on the reinforcement in the topping and a part of the concrete in the ribs, see Fig. 9.

For ComFlor 75 the composite slab is continuous over support B, see Fig. 8. This means that the steel deck will contribute to the hogging bending moment resistance.

According the documentation of the supplier, the contribution of the ComFlor 75 deck to the hogging bending moment resistance is $M_{p a . R d}=9.35 \cdot 1.8=16.83 \mathrm{kNm}$.

Table 3.Geometry of series 1 and 2

\begin{tabular}{cccc}
\hline Var. & TS1+TS2 & TS3 & TS4+TS5 \\
\hline$b_{1}[\mathrm{~mm}]$ & 175 & 175 & 173 \\
$b_{2}[\mathrm{~mm}]$ & 56 & 56 & 120 \\
$c_{1}[\mathrm{~mm}]$ & 23 & 25 & 37 \\
$c_{2}[\mathrm{~mm}]$ & 23 & 23 & 37 \\
$c_{3}[\mathrm{~mm}]$ & 40 & 40 & 24 \\
$d_{1}[\mathrm{~mm}]$ & 8 & 8 & 8 \\
$d_{2}[\mathrm{~mm}]$ & 8 & 10 & 8 \\
$d_{3}[\mathrm{~mm}]$ & 12 & 12 & 12 \\
$h[\mathrm{~mm}]$ & 280 & 280 & 150 \\
$h_{a}[\mathrm{~mm}]$ & 210 & 210 & 60
\end{tabular}

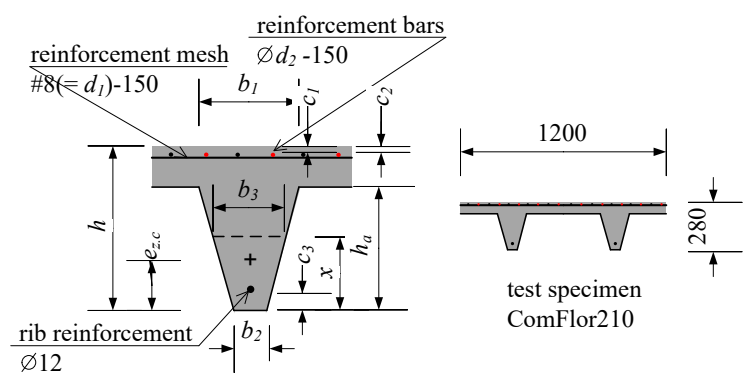

Fig. 9. Cross-section TS1 to TS3 (ComFlor 210).

Based on the actual yield stress $402 \mathrm{MPa}$, the hogging bending moment resistance is $M_{p a . R d}=16.83 \cdot \frac{402}{350}=19.35 \mathrm{kNm}$.

This contribution of the deck ComFlor 75 is added to the contribution based on the reinforcement in the topping and a part of the concrete in the ribs.

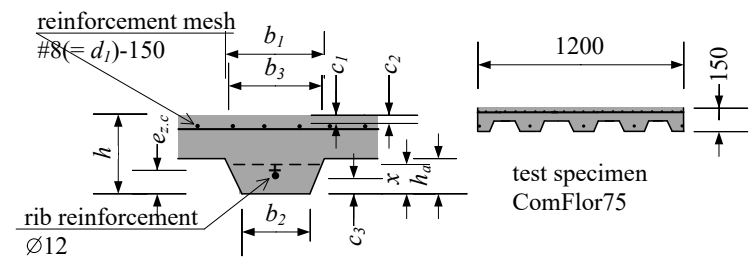

Fig. 10. Cross-section TS4 and TS5 (ComFlor 75).

The results are summarised in Table 4 for both series. 
Table 4. Results of series 1 and 2

\begin{tabular}{cccccc}
\hline Var. & TS1 & TS2 & TS3 & TS4 & TS5 \\
\hline Nr. Ø8 bars $[-]$ & 15 & 15 & 8 & 15 & 15 \\
Nr. Ø 10 bars [-] & - & - & 7 & - & - \\
$f_{c}[\mathrm{MPa}]$ & 39.9 & 41.5 & 41.8 & 42.1 & 43.6 \\
$M_{R d .1}^{-}[\mathrm{kNm}]$ & 107.2 & 107.3 & 134.0 & - & - \\
$M_{R d .2}^{-}[\mathrm{kNm}]$ & 83.5 & 84.5 & 98.3 & 60.8 & 61.1 \\
$V_{R d . c}[\mathrm{kN}]$ & 58.4 & 58.7 & 61.1 & 89.6 & 90.4 \\
$V_{R d . c . B}[\mathrm{kN}]$ & 888.9 & 900.9 & 889.5 & - & -
\end{tabular}

With:

$M_{R d .1}^{-}$hogging bending moment resistance based on the concrete beam at support B

$M_{R d .2}^{-}$hogging bending moment resistance based on the concrete ribs of the composite slab $V_{\text {Rd.c }}$ vertical shear resistance based on the concrete ribs of the composite slab

$V_{\text {Rd.c. } B}$ vertical shear resistance based on the concrete beam at support B

\section{Test results}

\subsection{Determination of $M$ and $V$ in the critical cross-sections}

The maximum line load by the hydraulic jack causes a hogging bending moment and a vertical shear force. The hogging bending moment and the vertical shear force will be influenced by the self-weight of the test specimen and the dead load $P_{1}$ and $P_{2}$ of the spreader beams, respectively at support $A$ and at the load introduction.

The self-weight of the slab is not uniformly distributed, especially due to the concrete beam at both edges of the slab and the encased steel beam at the intermediate support B of series 1 with the deep deck ComFlor 210, see Fig. 11.

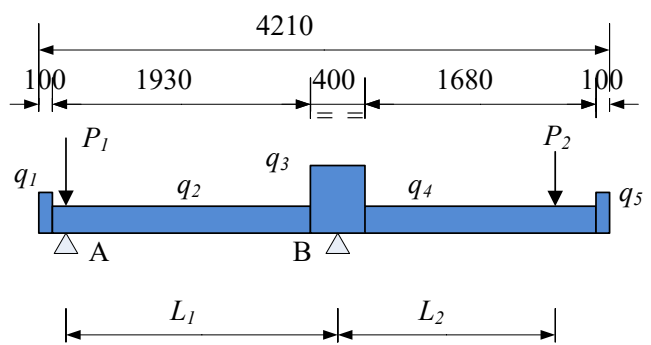

Fig. 11. Loading scheme of series 1 .

The loading scheme of series 2 (ComFlor 75) without an encased steel beam at support B is shown in Fig. 12.

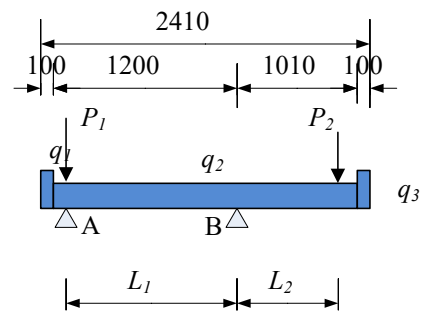

Fig. 12. Loading scheme of series 2 .

The values of these uniformly distributed loads and the concentrated loads as shown in Figure 11 and 12 for respectively series 1 and 2 are presented in Table 5, including the span $L_{1}$ between supports A and $\mathrm{B}$ and the position $L_{2}$ of the load introduction.

Table 5. Overview of the dead loads TS1 to TS5

\begin{tabular}{cccccc}
\hline Var. & TS1 & TS 2 & TS3 & TS4 & TS5 \\
\hline$q_{1}[\mathrm{kN} / \mathrm{m}]$ & 9.0 & 9.0 & 9.0 & 4.5 & 4.5 \\
$q_{2}[\mathrm{kN} / \mathrm{m}]$ & 3.35 & 3.35 & 3.35 & 3.50 & 3.50 \\
$q_{3}[\mathrm{kN} / \mathrm{m}]$ & 12.65 & 12.65 & 12.65 & 4.50 & 4.50 \\
$q_{4}[\mathrm{kN} / \mathrm{m}]$ & 3.35 & 3.35 & 3.35 & - & - \\
$q_{5}[\mathrm{kN} / \mathrm{m}]$ & 9.0 & 9.0 & 9.0 & - & - \\
$P_{1}[\mathrm{kN}]$ & 2.7 & 2.7 & 2.7 & 2.7 & 2.7 \\
$P_{2}[\mathrm{kN}]$ & 4.8 & 4.8 & 4.8 & 4.8 & 4.8 \\
$L_{1}[\mathrm{~mm}]$ & 1970 & 1950 & 1970 & 1100 & 1100 \\
$L_{2}[\mathrm{~mm}]$ & 1620 & 915 & 915 & 660 & 330
\end{tabular}

Two cross-sections are distinguished for the test specimens of series 1 , namely section I-I located in the centre of support B and section II-II located at the right side of the encased beam of support B, see Fig. 7. In section I-I there is the steel section HE200A, encased in a concrete beam with a width of $400 \mathrm{~mm}$. The cross-section in section II-II at the edge of the concrete beam is the normal ribbed section. The hogging bending moment resistance as well as the vertical shear resistance of section II-II is smaller than of section I-I.

The combination of hogging bending moment and vertical shear is different for these two cross-sections, see Fig. 13. The maximum hogging bending moment is acting at support $\mathrm{B}$. The vertical shear force at this support is different at the left side $R_{B L}$ and at the right side $R_{B R}$.

For TS4 and TS5 of series 2 there is only one critical cross-section, namely the section located in the centre of support B. 


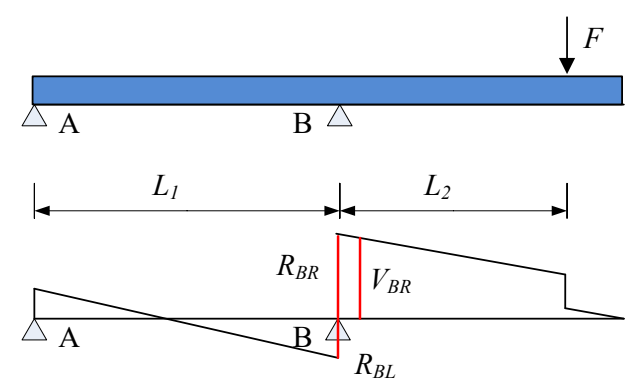

Fig. 13. Vertical shear distribution.

Table 6 shows the combinations $R_{B R}-M_{B}$ for section I-I for both series and the combination $V_{B R}-M_{B R}$ for section II-II for series 1 due to the dead load only. The combination with a vertical shear force $R_{B L}$ is not shown, because the load effect of the hydraulic jack acting on the right hand side is governing.

Table 6.Overview of combinations vertical shear - hogging bending moment due to dead load

\begin{tabular}{cccccc}
\hline Var. & TS1 & TS 2 & TS3 & TS4 & TS5 \\
\hline$R_{D L . B R}[\mathrm{kN}]$ & 13.86 & 13.86 & 13.86 & 8.79 & 8.79 \\
$M_{D L . B}[\mathrm{kN} / \mathrm{m}]$ & -15.62 & -12.24 & -12.24 & -5.43 & -3.85 \\
$V_{D L . B R}[\mathrm{kN}]$ & 11.33 & 11.33 & 11.33 & - & - \\
$M_{D L . B R}[\mathrm{kN} / \mathrm{m}]$ & -13.10 & -9.72 & -9.72 & - & -
\end{tabular}

\subsection{Results of test series 1 (Com Flor 210)}

Fig. 14 shows the $P-\delta$ diagrams of series 1 .

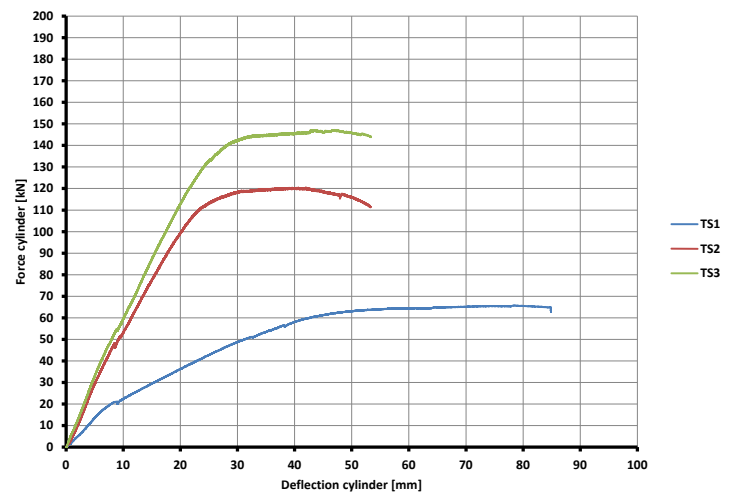

Fig. 14. P- $\delta$ diagram of TS1 to TS3.

The applied hogging bending moment is, based on the cylinder load and the influence of the dead load:

$M_{u \cdot T S . B}=F_{u} \cdot L_{2}+M_{D L . B} \quad$ (section 1 Fig.7)

Or:

$M_{u . T S . B R}=F_{u} \cdot\left(L_{2}-0.2\right)+M_{D L . B R}$ (section 2 Fig.

7)

In which $F_{u}$ is the cylinder load at failure.

Some observations during the test and the failure loads are given below.
TS1

The location $L_{2}$ of TS1 is $1620 \mathrm{~mm}$, the largest of test series 1 . The slab failed at an applied load of $F_{u}=64.45 \mathrm{kN}$ and the maximum deflection of the cylinder is $85 \mathrm{~mm}$. The test specimen failed in bending at section 1 of support B, where the largest hogging bending moment is acting. Rather big cracks at the top of TS1 appeared. Shear cracks in the crosssection did not appear.

In the $P-\delta$ diagram in Fig. 14 the effect of the concrete cracking is visible at a cylinder load of $21 \mathrm{kN}$. The reinforcement of the mesh yields at a cylinder load of $57 \mathrm{kN}$.

The ultimate bending moment $M_{u, T S 1 . B}$ is: $M_{u . T S 1 . B}=64.45 \cdot 1.62+15.62=121.03 \mathrm{kNm}$

\section{TS2}

The location $L_{2}$ of TS2 is $915 \mathrm{~mm}$. The slab failed at an applied load of $F_{u}=120.40 \mathrm{kN}$. The maximum deflection of the cylinder is 53 $\mathrm{mm}$. This test specimen failed also in bending. Rather big cracks at the top of TS2 appeared at the left side of support B.

In the $P-\delta$ diagram in Fig. 14 the effect of the concrete cracking is visible at a cylinder load of $48 \mathrm{kN}$. The reinforcement of the mesh yields at a cylinder load of $100 \mathrm{kN}$.

The ultimate bending moment $M_{u . T S 2 . B}$ is: $M_{u . T S 2 . B}=120.40 \cdot 0.915+12.24=122.64 \mathrm{kNm}$ The difference with the hogging bending moment resistance of TS1 is very small, only $2 \%$. It is clear that the ultimate bending moment is not influenced by the vertical shear force.

\section{TS3}

The location $L_{2}$ of TS3 is $915 \mathrm{~mm}$. The difference with TS2 is that the additional reinforcement is $\varnothing 10-150$ instead of $\varnothing 8-150$ .This results in a higher cylinder load at failure, namely $147,18 \mathrm{kN}$, and the maximum deflection of the cylinder is $53 \mathrm{~mm}$.

The test specimen failed in bending. Rather big cracks at the top of TS3 appeared at the left side of support B.

In the $P-\delta$ diagram in Fig. 14 the effect of the concrete cracking is visible at a cylinder load of around $54 \mathrm{kN}$. The reinforcement of the mesh yielded at a cylinder load of around $123 \mathrm{kN}$. The ultimate bending moment $M_{u . T S 3 . B}$ is:

$$
M_{u . T S 3 . B}=147.18 \cdot 0.915+12.24=146.91 \mathrm{kNm}
$$




\subsection{Results test series 2 (ComFlor 75)}

Figure 15 shows the $P-\delta$ diagrams of TS4 and TS5, The test specimens are individually described in the next paragraphs.

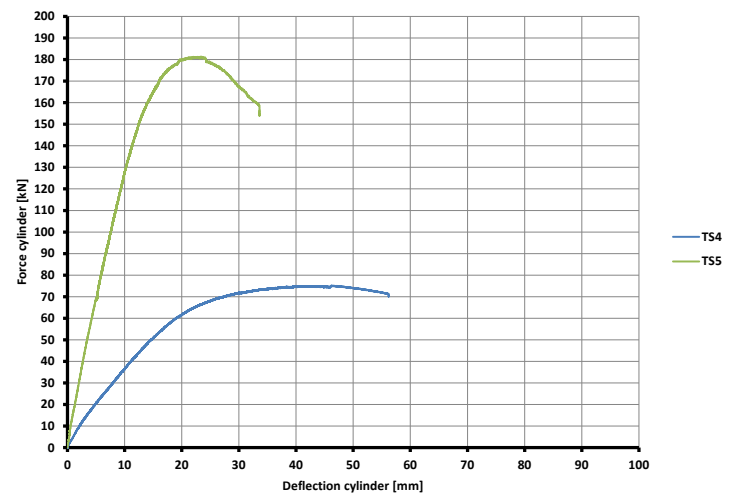

Fig. 15. $P-\delta$ diagram of TS4 and TS5.

\section{TS4}

The location $L_{2}$ of TS4 is $660 \mathrm{~mm}$. The slab failed at an applied load of $F_{u}=75.15 \mathrm{kN}$. The maximum deflection of the cylinder is $57 \mathrm{~mm}$.

The test specimen failed in bending. Rather big cracks at the top of TS4 appeared at the left side of support B. The effect of concrete cracking was visible at a cylinder load of around $36 \mathrm{kN}$. The reinforcement of the mesh yielded at a cylinder load of around $58 \mathrm{kN}$.

The ultimate bending moment $M_{u . T S 4}$ is:

$M_{u . T S 4}=75.15 \cdot 0.660+5.34=54.94 \mathrm{kNm}$

There were some problems with the set-up of support B near the end of the test. Load cells B3 up to B5 did not register the reaction forces during testing. It was observed that due to the width of the ribs of the deck local crushing failure of the bottom of a rib occurred.

\section{TS5}

For TS5 an additional strip is placed at the bottom of the ribs to avoid local failure of the rib of the deck.

The location $L_{2}$ of TS5 is $330 \mathrm{~mm}$. This results in a high cylinder load at failure, The slab failed at an applied load of $F_{u}=181.38 \mathrm{kN}$. The maximum deflection of the cylinder is 33 $\mathrm{mm}$.

The test specimen failed in bending. The effect of concrete cracking was visible at a cylinder load of around $68 \mathrm{kN}$. The reinforcement of the mesh yielded at a cylinder load of around $131 \mathrm{kN}$.
The ultimate bending moment $M_{u . T S 5}$ is: $M_{u . T S 5}=181.38 \cdot 0.330+3.85=63.71 \mathrm{kNm}$

It is remarkable that the ultimate hogging bending moment of TS5 is much higher than the ultimate hogging bending moment of TS4, which is explained by the local failure of the support of some ribs of TS4.

Table 7 shows the results of both series.

Table 7.Test results, hogging bending moments and corresponding vertical shear forces

\begin{tabular}{cccccc}
\hline Var. & TS1 & TS2 & TS3 & TS4 & TS5 \\
\hline$R_{\text {jack }}[\mathrm{kN}]$ & 64.5 & 120.4 & 147.2 & 75.2 & 181.4 \\
$R_{B R}[\mathrm{kN}]$ & 79.6 & 134.3 & 161.0 & 83.9 & 190.2 \\
$M_{u . B}[\mathrm{kNm}]$ & 121.0 & 122.6 & 146.9 & 54.9 & 63.7 \\
$V_{B R}[\mathrm{kN}]$ & 77.1 & 113.7 & 158.5 & - & - \\
$M_{u . B R}[\mathrm{kNm}]$ & 106.5 & 95.8 & 115.0 & - & -
\end{tabular}

\section{Evaluation recommendations}

and

design

\subsection{Test series 1 (ComFlor 210)}

All three test specimens failed in bending and the measured ultimate moment, see Table 7 , is greater than calculated, see Table 4 . So the design model used for the calculation is safe. Comparison of TS1 (smaller vertical shear) with TS2 (greater vertical shear) show that there is no interaction between $M$ and $V$.

The calculated values for the vertical shear resistance $V_{R d . c}$, see Table 4, are based on the model in EC 4 without taking into account the contribution of the decking profile. None of the specimen failed in vertical shear and therefore the values in the table must be considered as lower bound values for the actual resistance. The results $R_{B R}$ of TS2 and TS3 show that the model in EC4 considerably underestimates the actual vertical shear resistance.

If the vertical shear resistance is determined as the sum of the vertical shear resistance of the decking profile and the vertical shear resistance of the concrete rib the value of $V_{B R}$ is much smaller, $V_{B R}=112 \mathrm{kN}<161 \mathrm{kN}$.

Conclusion is that the vertical shear resistance in the test exceeded the sum of the vertical shear resistance of the decking profile and the vertical shear resistance of the concrete rib. 


\subsection{Test series 2 (Com Flor 75)}

Test specimen TS4 failed by unforeseen local crushing of the rib as described in Chapter 3.2. The registered hogging moment was $7.5 \%$ less than the calculated value. There was no sign of vertical shear failure.

The calculated values for the vertical shear resistance $V_{R d . c}$ in Table 4 are based on the model in EC 4 without taking into account the contribution of the decking profile. The result $R_{B R}$ of TS5 in Table 7 shows that the model in EC 4 considerably underestimates the actual vertical shear resistance $V_{R d . c}$ in Table 4. As the specimen did not fail in vertical shear the value in the table must be considered as a lower bound value for the actual resistance.

If the vertical shear resistance is determined as the sum of the vertical shear resistance of the decking profile and the vertical shear resistance of the concrete rib the value of $V_{B R}$ is:

$$
V_{B R}=171.2 \mathrm{kN}<190.2 \mathrm{kN}
$$

This confirms that for hogging bending the same model can be used as proposed by Stark [3] for sagging bending.

\section{Summary and conclusions}

Tata Steel Panels and Profiles and Dutch Engineereing r.i. BV commissioned Stevin II laboratory of Delft University of Technology to carry out a research program to investigate the interaction between hogging moment and vertical shear in composite slabs with ComFlor 210 and ComFlor 75. A test program was carried out to gain more insight in the interaction and to find out whether design calculations should take into account $M-V$ interaction when applying the Comflor series. Two series of respectively three and two test specimens were conducted, namely on ComFlor 210 (TS1 up to TS3) and ComFlor 75 (TS4 and TS5).

A second point of interest is the contribution of the steel deck to the vertical shear resistance.

Based on the results of the test specimens, the following is concluded:

- The design model for the calculation of the hogging moment resistance of ComFlor 210 , based on the rules for shallow decking in EN1994-1-1, is safe.
- The vertical shear force does not influence the hogging bending moment resistance for ComFlor 210

- The vertical shear resistance of ComFlor 210 is much higher than based on the vertical shear resistance of the concrete in the ribs only as suggested in EN1994-1-1 which refers to EN1992-1-1

- The suggestion of Hartmeyer [4] that the vertical shear resistance may be determined as the sum of the vertical shear resistance of the decking profile and the vertical shear resistance of the concrete components is confirmed by the tests.

- The vertical shear force doesn't influence the hogging bending moment resistance for ComFlor 75 (refers to ComFlor 60 in the UK)

- The vertical shear resistance may be determined as the sum of the vertical shear resistance of the decking profile and the vertical shear resistance of the concrete rib. This confirms that for hogging bending the same model can be used as proposed by Stark [3] for sagging bending.

\section{References}

[1] NEN-EN 1994-1-1 (Eurocode 4), Design of composite steel and concrete structures Part 1-1: General rules and rules for buildings; 2005.

[2] NEN-EN 1992-1-1 (Eurocode 2), Design of concrete structures - Part 1-1: General rules and rules for buildings; 2005.

[3] Stark Partners. Report: Vertical shear resistance of composite floors with ComFlor 60.

[4] Hartmeyer SS. Dissertation: Ein Modell zur Beschreibung des Querkrafttragverhaltnes von Stahlverbunddecken aus Leicht- und Normalbeton, Kaiserslautern; 2014.

[5] Tuls JJ. Influence of a vertical shear force on the hogging bending moment resistance in composite slabs', Master thesis, Delft University of Technology, Delft; 2017. 